\title{
Fast-track anesthesia in lateral mini-thoracotomy for transapical transcatheter valve implantation
}

\author{
Ali Haddad ${ }^{1}$, Cynthia Szalai ${ }^{1}$, Lena van Brakel ${ }^{2}$, Yacine Elhmidi ${ }^{3 \#}$, Sven Arends ${ }^{1}$, Marco Rabis ${ }^{1}$, Anca Pop ${ }^{1}$, \\ Arjang Ruhparwar ${ }^{2}$, Thorsten Brenner ${ }^{1}$, Sharaf-Eldin Shehada ${ }^{2 \#} \wedge$ \\ ${ }^{1}$ Department of Anesthesiology and Intensive Care Medicine, West German Heart and Vascular Center, University Hospital Essen, University \\ Duisburg-Essen, Duisburg, Germany; ${ }^{2}$ Department of Thoracic and Cardiovascular Surgery, West German Heart and Vascular Center, University \\ Hospital Essen, University Duisburg-Essen, Duisburg, Germany; ${ }^{3}$ Department of Cardiac Surgery, Ludwigshafen Heart Centre, Ludwigshafen, \\ Germany \\ Contributions: (I) Conception and design: Ali Haddad, SE Shehada; (II) Administrative support: A Haddad, SE Shehada, A Ruhparwar; (III) Provision \\ of study materials or patients: A Haddad, SE Shehada, C Szalai; (IV) Collection and assembly of data: LV Brakel; (V) Data analysis and interpretation: \\ A Haddad, SE Shehada, Y Elhmidi; (VI) Manuscript writing: All authors; (VII) Final approval of manuscript: All authors. \\ \#These authors contributed equally to this work. \\ Correspondence to: Ali Haddad, MD. Department of Anesthesiology and Intensive Care Medicine, University Hospital Essen, University Duisburg- \\ Essen, Germany. Email: ali.haddad@uk-essen.de.
}

Background: Patients who undergo transapical transcatheter aortic/mitral valve implantation are at higher risk of morbidity and mortality than those undergoing transvascular procedures. In addition, these patients have prolonged intensive care and hospital courses. Fast-track anesthesia could reduce perioperative complications and admission stays in such patients.

Methods: This retrospective single-center study, evaluates six high-risk patients undergoing transapical valve implantation between 01/2020 till 01/2021. All patients received a paravertebral block (PVB) as part of a fast-track approach. The airway was secured with a Gastro-double-lumen laryngeal mask which includes one orifice was for ventilation and one for the transesophageal echocardiography probe. Anesthesia was maintained with a volatile anesthetic (Sevoflurane MAC 1\%). Immediately post procedure, all patients were awakened and admitted to the intermediate/intensive-care unit.

Results: Three patients were females, mean age $=71 \pm 6$ years, patients' risk profiles were high (mean Log. EuroSCORE-I 22\% \& STS-PROM 10\%). No incidents of re-intubation, atelectasis/pneumonia, low output syndrome, stroke, dialysis, pacemaker implantation or operative mortality were reported. One patient (16.7\%) underwent re-exploration for bleeding and developed a wound infection. Postoperative pain scores showed that no patient required additional analgesics after the initial eight hours post procedure. Mean postoperative intermediate/intensive-care stay was $13.8 \pm 3.2$ hours and patients were mobilized early and discharged to the normal ward.

Conclusions: Fast-track anesthesia using paravertebral-blockade for transcatheter transapical valve replacement in high-risk patients is a possible anesthetic approach. An effective PVB, in addition to a doublelumen laryngeal mask, provide an alternative strategy to conventional general anesthesia. These promising results could encourage further consideration of this approach in similar cardiac surgery patients.

Keywords: Paravertebral-block; high-risk cardiac patients; transapical valve implantation; fast-track cardiac surgery

Submitted Apr 29, 2021. Accepted for publication Jul 14, 2021.

doi: $10.21037 /$ jtd-21-751

View this article at: https://dx.doi.org/10.21037/jtd-21-751

^ ORCID: 0000-0003-1638-0493. 


\section{Introduction}

Aortic valve stenosis is one of the most common heart valve diseases worldwide (1) and has been treated for decades with surgical aortic valve replacement, either conservatively or with a minimally invasive approach $(2,3)$. Transcatheter aortic valve implantation (TAVI) has been adopted as an alternative for surgical aortic valve replacement initially in high-risk, then in intermediate-risk and more recently in low-risk patients (4-7). In Germany, the number of TAVI procedures has increased significantly from 2,198 in 2009 to 13,279 in 2018 , representing $57.5 \%$ of all isolated aortic valve procedures (8). More recently, the adoption of transcatheter mitral valve implantation (TMVI) is increasing in very high-risk and redo patients (9). Transfemoral aortic valve implantation (TF-TAVI) is considered the most common TAVI access-route and has become a routine for high-risk patients. Transapical valve implantation (TATAVI) is considered an alternative and less common route when trans-vascular routes are inappropriate. TA-TAVI requires surgical access via left lateral mini-thoracotomy and is usually performed under general anesthesia with endotracheal intubation. This often results in a complicated postoperative course, varying prolonged intubation times, respiratory complications, and increased intensive care and hospital stays.

Therefore, we introduced our fast-track anesthesia using the paravertebral block (PVB) for transapical valve implantation strategy aiming to reduce perioperative complication. Unlike thoracic epidural anesthesia (TEA), the PVB technique avoids contralateral sympatholytic symptoms, thereby minimizing hypotension and maintaining blood pressure during the procedure $(10,11)$. This study reports our primary experience on six patients undergoing transapical aortic +/- mitral valve implantation after implementing a multidisciplinary standardized treatment protocol.

We present the following article in accordance with the STROBE reporting checklist (available at https://dx.doi. org/10.21037/jtd-21-751).

\section{Methods}

\section{Study design}

The study employs a single-center retrospective approach, including high-risk patients undergoing transapical aortic +/- mitral valve implantation in our department between $01 / 2020$ and 01/2021. Patients' preoperative, operative and postoperative data were recorded in our institutional database. Thereafter, data were retrospectively extracted and evaluated. The study was conducted in accordance with the Declaration of Helsinki (as revised in 2013). The present study obtained IRB approval (Ref\# 20-9733-BO). All Patients signed and gave informed consent before taking part of this type of anesthesia and agreed to evaluate their data anonymously.

\section{Study endpoints}

Primary endpoint was mainly procedural success of the usage of fast-track anesthesia using PVB strategy for transapical aortic and mitral valve implantation. Secondary endpoints included intraoperative and early postoperative outcomes based on the VARC II criteria which include: function of the implanted valve(s), bleeding complications, vascular complications, myocardial infarction, acute kidney injury, stroke, pacemaker implantation, respiratory or wound complications and mortality.

\section{Preoperative management}

Based on the recommendations of an interdisciplinary valve-team involving cardiac surgeons, cardiologists and anesthetists, each patient's findings, surgical indication, access route, and bail-out strategy were evaluated. Once planned for surgery, a standardized medical regimen was established for all patients. Patients were declared for this type anesthesiologic management one day before the procedure and each of those patients signed written consent. Additionally, patients were requested to fast for at least 6 hours before the procedure to avoid the potential risk of aspiration.

\section{Anesthesiologic management}

An ultrasound guided thoracic PVB was performed in the left fourth and sixth paravertebral spaces (T4 \& T6) prior to induction of anesthesia. Patients received $0.3 \mathrm{~mL} / \mathrm{Kg} / \mathrm{BW}$ of $3.75 \mathrm{mg} / \mathrm{mL}$ Ropivacaine. The multi-injection technique was used to achieve a large spread of the local anesthetic agent. A radial artery and internal jugular central venous catheter were inserted under local anesthesia prior to induction of general anesthesia. No urinary catheter was inserted and an external urine collector was placed. For induction of anesthesia, patients received low-dose intravenous Fentanyl $(2 \mu \mathrm{gs} / \mathrm{Kg} / \mathrm{BW})$ and intravenous Etomidate $(0.2 \mathrm{mg} / \mathrm{Kg} / \mathrm{BW})$, a Gastro-double-lumen laryngeal mask was then inserted. 

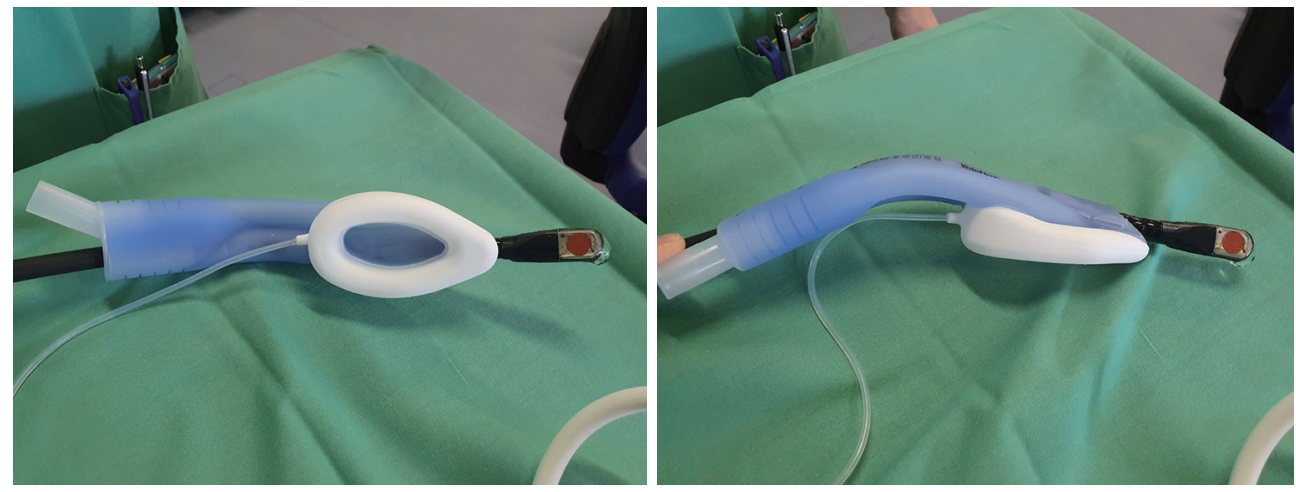

Figure 1 Double-lumen laryngeal mask: one orifice for ventilation and one for the transesophageal echocardiographic probe.

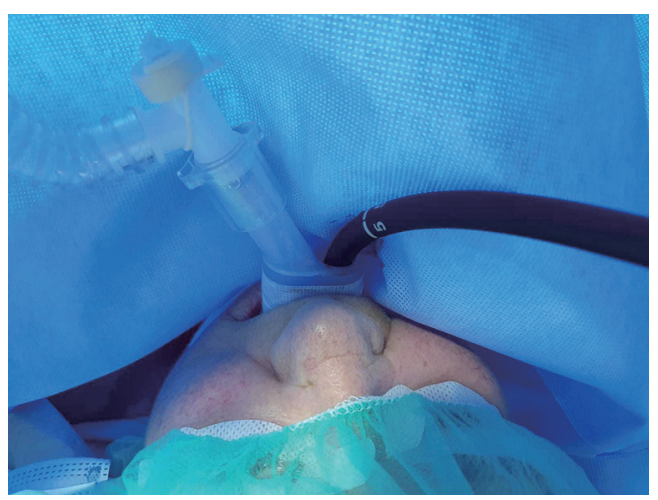

Figure 2 Intraoperative application of a double-lumen laryngeal mask for ventilation and TOE probe. TOE, transesophageal echocardiography.

These laryngeal masks have a double orifice, which allows ventilation and insertion of a transesophageal echocardiographic probe (Figures 1,2). Anesthesia was maintained with a volatile anesthetic agent (Sevoflurane with MAC $1 \%)$. Patients were initially ventilated via "intermittent positive pressure ventilation" (IPPV) with a tidal volume of $6 \mathrm{~mL} / \mathrm{Kg} / \mathrm{BW}$ and switched after valve implantation to "continues positive airway pressure" (CPAP)-Modus, subsequently the volatile was reduced to MAC-awake with MAC $0.3-0.5 \%$ towards the end of the procedure. Intraoperative catecholamines, if required (Norepinephrine), were then reduced by the end of the operation. Volume replacement therapy was carried out using a physiologic crystalloid-infusion (Jonosteril 500-750 mL). Echocardiography was performed pre- and post-intervention to allow step by step evaluation. Laryngeal masks were removed at emergence and patients were successfully transferred awake to the Intensive/Intermediate care unit
(ICU/IMC) for monitoring, then subsequently to the normal ward a couple of hours later. Postoperative pain evaluation was carried out, with the visual analogue scale (VAS) and the numerical rating scale (NRS) $(12,13)$, hourly up to 48 hours post operatively.

\section{Surgical management}

All patients underwent surgery via a left lateral mini thoracotomy $(5-7 \mathrm{~cm})$. At the lateral wall of the apex a small distance from the coronaries was marked and prepared with four double pledged sutures to protect the implantation site. A temporary pacemaker was attached to the ventricle. Thereafter, for the purpose of contrast injection during valve implantation, a $6 \mathrm{~F}$ pigtail catheter was placed within the non-coronary sinus over a smooth J-wire via the femoral artery to mark the aortic root. Apical puncture, insertion of a smooth wire through the native valve, then the valve system sheath was then undertaken. The prosthesis was introduced and placed into the correct position (either aortic or mitral) over a stiff wire. Valve implantation was performed under apnea and rapid pacing (180 pbm for aortic valve and $120 \mathrm{pbm}$ for mitral valve). Then, the stiff wire, valve-system, sheath, and the pigtail catheter were then removed. The apical incision was secured by knotting the four sutures. Finally, a $24 \mathrm{~F}$ drainage was inserted into the left pleura, followed by hemostasis and wound closure.

\section{Echocardiography}

Transesophageal echocardiography (TOE) was performed prior to and immediately after valve implantation in all patients. TOE was performed with multiplane sector ultrasound transducers (GE 6Tc-RS, 3.0-8.0. MHz or GE 6VT-D, 3.0-8.0. MHz 
probes) and GE Vivid S6, GE Vivid S70 ultrasound machines (GE Healthcare GmbH, Solingen, Germany).

\section{Statistical analysis}

Statistical analysis was performed using the SPSS-software (version 22.0. IBM Crop., Armonk, NY, USA). Continuous data were expressed as mean \pm standard deviation (SD). Categorical data were expressed as frequencies and percentages.

\section{Results}

\section{Patient population}

Six ( 3 females and 3 males) patients (mean age $71 \pm 6$ years, range, 62 to 77 years) with aortic valve stenosis and mitral valve stenosis presented with high-risk profiles (mean Log. EuroSCORE-I 22\% \& STS-PROM 10\% for either aortic and mitral transapical valve implantation. These patients were not eligible for conventional cardiac surgery or transvascular transcatheter valve implantation. All patients presented with heart insufficiency (NYHA class III-IV), right ventricular dysfunction and pulmonary hypertension in their medical history. All patients presented with reduced general condition and two of them had cardiac cachexia, two patients presented with malignancy. Two patients had previous cardiac surgery and three patients required an urgent/emergent intervention. Details of patients' baseline characteristics are listed in Table 1.

\section{Anesthesiologic outcomes}

Table 2 summarizes the anesthesiologic management. All patients received regional anesthesia before induction. The PVB was performed with two separate single shots at the $4^{\text {th }} \&$ $6^{\text {th }}$ thoracic paravertebral space. Under ultrasound guidance, paravertebral space was identified and blocked in most patients (83.3\%). In one patient (16.7\%), a block failure was noted, as the paravertebral space was anatomically challenging to identify, and the local anesthetic solution did not spread properly. This patient reported severe pain immediately on arrival to the IMC, which required insertion of a successful second PVB at both levels with $80 \mathrm{mg}$ Ropivacaine.

\section{Perioperative and pain outcomes}

Intraoperative and postoperative surgical related outcomes are expressed in Tables 3,4. All procedures were reported as successful. Four patients underwent transapical aortic valve implantation and one patient underwent mitral valve implantation and one patient a dual, aortic and mitral valve implantation. The mean procedural time was $65 \pm 8$ minutes. Echocardiographic control at the end of procedure reported good position and functioning of the prosthesis with minimal or no paravalvular leakage. All patients were admitted to the ICU/IMC unit awake and in sinus rhythm. Mean postoperative intermediate/intensive-care stay was $13.8 \pm 3.2$ hours. The pleura drain was removed after 24 hours, and patients were all swiftly mobilized. Postoperative pain evaluation showed that the five other patients needed low dose adjuvant analgesics (opioid or metamizole) within the first eight hours postoperatively. Three patients developed nausea without vomiting after receiving opioid agents within the first 8 hours. For the remaining 48 hours, none of the patients required any further analgesics. Detailed pain scoring and management are reported in Table 5.

Postoperative results reported no incidence of reintubation, pneumonia, low output syndrome, stroke, dialysis requirement, pacemaker implantation or operative mortality. One patient (16.7\%) underwent re-exploration for bleeding on the third postoperative day and developed wound infection three months later.

\section{Discussion}

The main findings of this study show: (I) fast-track anesthesia using a PVB is feasible in patients with high-risk profiles undergoing transapical valve implantation. (II) PVB, in addition to double lumen laryngeal mask, provide an alternative strategy to general anesthesia with intubation. (III) Fast recovery with minimum or no operative complications was observed.

The present study describes a series of six patients with severe aortic valve stenosis and in two cases, combined mitral valve lesions with severe stenosis and moderate insufficiency. After implementing of a multidisciplinary, standardized treatment protocol, the indication for transcatheter transapical aortic and mitral valve replacement was established. Such patients are at high-risk for mortality and morbidity and may therefore benefit from fast-track anesthesiologic management. We performed regional anesthesia approach (a PVB) to minimize intra- and postoperative opioid consumption (14). Previous investigators reported that high intraoperative opioid requirements increase readmission risk in patients undergoing ambulatory 
Table 1 Baseline data

\begin{tabular}{|c|c|c|c|c|c|c|}
\hline Variable & Patient \#1 & Patient \#2 & Patient \#3 & Patient \#4 & Patient \#5 & Patient \#6 \\
\hline Age, years & 65 & 62 & 72 & 77 & 72 & 75 \\
\hline Gender, female & Yes & No & Yes & No & Yes & No \\
\hline BMI, $\mathrm{kg} / \mathrm{m}^{2}$ & 35.6 & 27.3 & 17.1 & 23 & 20.8 & 26.7 \\
\hline COPD & No & No & No & Yes & Yes & No \\
\hline Hypertension & Yes & Yes & Yes & Yes & Yes & Yes \\
\hline Diabetes mellitus & Yes & Yes & No & No & No & Yes \\
\hline Hyperlipidemia & Yes & Yes & No & Yes & No & Yes \\
\hline Renal transplantation & Yes & No & No & No & No & No \\
\hline Peripheral vascular disease & Yes & Yes & Yes & Yes & Yes & Yes \\
\hline Malignancy & No & Yes & No & No & No & Yes \\
\hline Reduced general condition & Yes & Yes & Yes & Yes & Yes & Yes \\
\hline Poor mobility & No & Yes & No & No & No & Yes \\
\hline Urgent/emergent indication & Yes & No & Yes & No & No & Yes \\
\hline \multicolumn{7}{|l|}{ Cardiac history } \\
\hline Previous cardiac surgery & Yes & No & Yes & No & No & No \\
\hline Pulmonary hypertension & Yes & Yes & Yes & Yes & Yes & Yes \\
\hline \multicolumn{7}{|l|}{ Valvular lesions } \\
\hline Aortic valve & AS III + ARI & AS III & Prosthesis & AS III & AS III & AS III + AR I \\
\hline Mitral valve & MS III + MRII & MRI & MS III, MR II & MRI & MRI & MRI \\
\hline Tricuspid valve & TR I & & TR II & & & TR I \\
\hline \multicolumn{7}{|l|}{ Risk scores } \\
\hline EuroSCORE-I (log.), \% & 51.75 & 13.57 & 22.9 & 24.26 & 28.3 & 23.18 \\
\hline EuroSCORE-II, \% & 37.14 & 4.72 & 1.53 & 14.34 & 8 & 5.98 \\
\hline STS-PROM, \% & $\mathrm{n} / \mathrm{a}$ & 3.733 & 26.872 & 3.042 & 10.853 & 6.2 \\
\hline
\end{tabular}

COPD, chronic obstructive pulmonary disease; NYHA, New York Heart Association; LV-EF, left ventricular ejection fraction, IRVF, impaired right ventricular function. AS/AR, aortic valve stenosis/regurgitation; MS/MR, mitral valve stenosis/regurgitation; TR, tricuspid valve regurgitation, EuroSCORE, European System for Cardiac Operative Risk Evaluation; STS-PROM, Society of Thoracic Surgery Predicted Risk of Mortality. 
Table 2 Perioperative anesthesia management

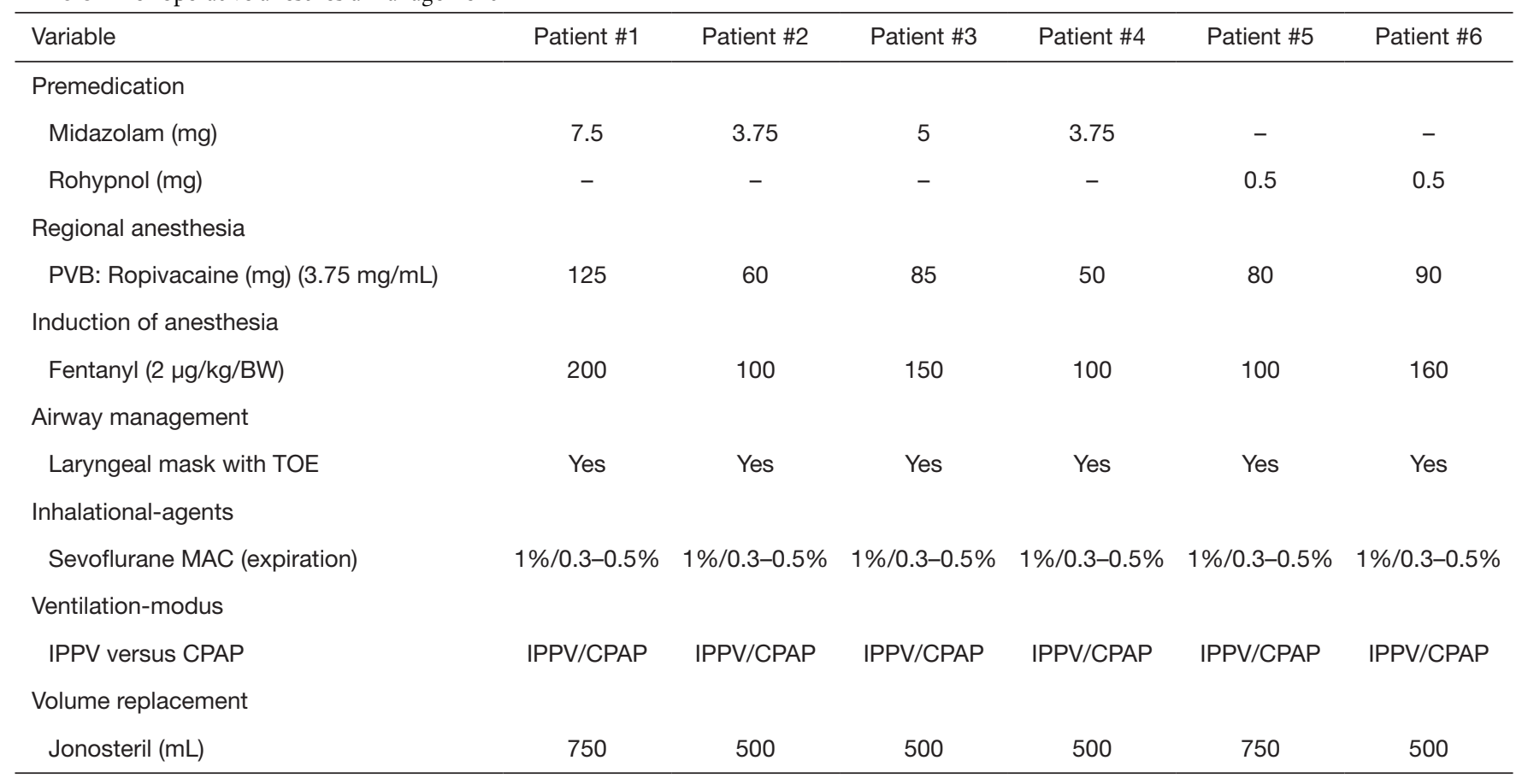

BW, body weight; PVB, paravertebral Block; TOE, transesophageal echocardiography; MAC, minimum alveolar concentration, IPPV, intermittent positive pressure ventilation, CPAP, continuous positive airway pressure.

Table 3 Intraoperative outcomes

\begin{tabular}{|c|c|c|c|c|c|c|}
\hline Variable & Patient \#1 & Patient \#2 & Patient \#3 & Patient \#4 & Patient \#5 & Patient \#6 \\
\hline \multicolumn{7}{|l|}{ Preoperative echocardiography } \\
\hline Aortic valve pathology & AS III + AR I & AS III + AR I & AS I & AS III & AS III & AS III + ARII \\
\hline sysPAP, mmHg & 62 & 55 & 80 & 65 & 45 & 37 \\
\hline $\mathrm{P}_{\text {max }} / \mathrm{P}_{\text {mean }}, \mathrm{mmHg}$ & $36 / 20$ & $48.2 / 24.9$ & $9.5 / 3.2$ & $68.9 / 37.7$ & $33 / 18$ & $30 / 18$ \\
\hline Aortic valve area, $\mathrm{cm}^{2}$ & 0.9 & 0.8 & 1.5 & 0.5 & 0.8 & 0.45 \\
\hline $\mathrm{P}_{\text {max }} / \mathrm{P}_{\text {mean }}, \mathrm{mmHg}$ & $15 / 8.4$ & - & $23 / 10$ & - & - & - \\
\hline Mitral valve area, $\mathrm{cm}^{2}$ & 1.4 & - & 1.46 & - & - & - \\
\hline \multicolumn{7}{|l|}{ Operative data } \\
\hline Blood transfusion, $\mathrm{mL}$ & 0 & 0 & 0 & 0 & 0 & 0 \\
\hline Surgical complications & No & No & No & No & No & No \\
\hline Procedural time, min & 69 & 74 & 66 & 71 & 64 & 51 \\
\hline Heart rhythm after procedure & SR & SR & SR & SR & SR & $S$ \\
\hline
\end{tabular}

AS/AR, aortic valve stenosis/regurgitation; MS/MR, mitral valve stenosis/regurgitation; sysPAP, systolic pulmonary artery pressure; $\mathrm{P}_{\text {max }} /$ $\mathrm{P}_{\text {mean }}$, pressure gradient maximal/mean; TAVI/TMVI, transcatheter aortic/mitral valve implantation; SR, Sinus Rhythm. 
Table 4 Postoperative outcomes

\begin{tabular}{|c|c|c|c|c|c|c|}
\hline Variable & Patient \#1 & Patient \#2 & Patient \#3 & Patient \#4 & Patient \#5 & Patient \#6 \\
\hline Leakage over aortic prosthesis & No & No & No & Trivial & No & No \\
\hline Gradient over aortic prosthesis, $\mathrm{P}_{\max } / \mathrm{P}_{\text {mean }}, \mathrm{mmHg}$ & $4 / 2.4$ & $10.8 / 5.3$ & $9.5 / 3.2$ & $14 / 7$ & $5.3 / 2.3$ & $4.6 / 2.2$ \\
\hline Leakage over mitral prosthesis & No & - & No & - & - & - \\
\hline \multicolumn{7}{|l|}{ Postoperative outcomes } \\
\hline Intensive or intermediate-care stay, hours & 15 & 14 & 10 & 18 & 11 & 15 \\
\hline Blood transfusion, $\mathrm{mL}$ & 600 & 0 & 1,200 & 0 & 600 & 0 \\
\hline Re-exploration for bleeding & No & No & Yes & No & No & No \\
\hline Myocardial infarction & No & No & No & No & No & No \\
\hline New dialysis & No & No & No & No & No & No \\
\hline Respiratory complications & No & No & No & No & No & No \\
\hline Stroke & No & No & No & No & No & No \\
\hline Pacemaker implantation & No & No & No & No & No & No \\
\hline Operative mortality & No & No & No & No & No & No \\
\hline Postoperative MACCE & No & No & No & No & No & No \\
\hline
\end{tabular}

$\mathrm{P}_{\text {max }} / \mathrm{P}_{\text {mean }}$, pressure gradient maximal/mean; LCOS, low cardiac output syndrome, MACCE, major adverse cardiac and cerebrovascular events.

surgery $(15,16)$.

During general anesthesia with endotracheal intubation, there is significant requirement for opioids and muscle relaxants. These may result in a residual neuromuscular blockade, prolonged intubation times, pulmonary complications, impaired wound healing, and a prolonged stay within the intensive care unit (16-19). Thoracic paravertebral blockade (PVB) provides equally effective analgesia compared to thoracic epidural anesthesia (TEA) for post-thoracotomy pain relief. Moreover, PVB causes fewer complications such as hypotension $(10,11)$. Patients in this series underwent a small left lateral mini thoracotomy for transcatheter transapical aortic and mitral valve implantation. These patients usually exhibit the most unstable hemodynamic changes; hence PVB should be considered an alternative to TEA in such patients $(20,21)$.

The operating room was kept at $23{ }^{\circ} \mathrm{C}$ and, a heating blanket was used to maintain normothermia. Regional anesthesia with PVB enables low dose anesthesia with a pre-valve implantation MAC of $1 \%$ and postvalve implantation MAC of $0.3-0.5 \%$. This facilitated less hemodynamic instability and low catecholamine requirement (Norepinephrine with $0.2-0.4 \mathrm{mg} / \mathrm{h}$ ) in these patients. The catecholamine support could be withdrawn with the beginning of CPAP-Modus under the MAC $0.3-0.5 \%$ after valve implantation. This approach made it feasible to perform echocardiography under spontaneous assisted ventilation (CPAP), allowing a stable hemodynamic and respiratory state at the end of surgery, similar to the preoperative conditions (without catecholamine support, mechanical ventilation or volume overload).

The analgesic effect of regional anesthesia and the absence of muscle relaxation that a larynx mask affords, provide a positive postoperative benefit on lung function. Patients required no oxygen support and no $\mathrm{SpO}_{2}$ desaturation or pneumonia was reported. The avoidance of muscle relaxation reduces the rate of postoperative pulmonary complications (22); in addition to minimizing 
Table 5 Postoperative pain management

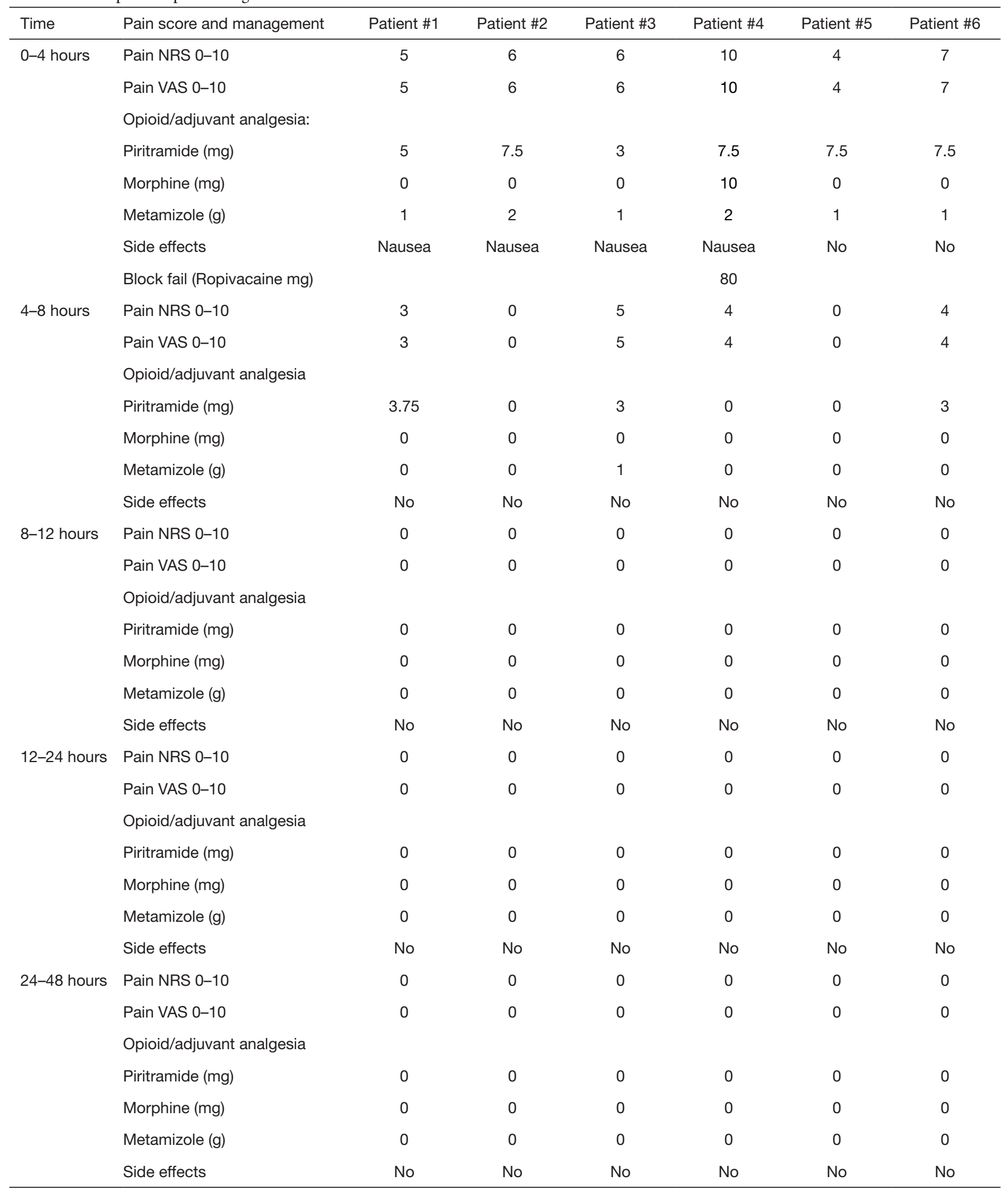

NRS, Numeric Rating Scale; VAS, Visual Analog Scale. 
mechanical ventilation time, maintaining spontaneous breathing positively affects right ventricular function, especially in this patient collective, who presented with pulmonary hypertension. The ICU/IMC course for all patients was uneventful, and patients were quickly mobilized and discharged to the normal ward. Postoperative pain evaluation was carried out using a numeric rating scale and a visual analogue scale from 0 to $10(12,13)$. One patient reported scores of 10 on immediate arrival to the IMC, secondary to ineffective PVB placement due to anatomical difficulty. This patient required repeated PVB at both levels with $80 \mathrm{mg}$ Ropivacaine, thereafter no further pain was reported. Other patients received adjuvant analgesics during the first eight postoperative hours, thereafter, they no pain was reported. Otherwise, three patients developed nausea as a side effect of opioid consumption.

One patient $(16.7 \%)$ who had mitral valve implantation underwent re-exploration for bleeding on the third postoperative day secondary to a coagulopathy caused by excessive heparinization because of a previous mechanical aortic valve. The patient was discharged seven days later but developed a superficial wound infection three months post discharge. No incidence of re-intubation, atelectasis/pneumonia, low output syndrome, stroke, dialysis, pacemaker implantation or operative mortality was reported.

The study indicates that fast-track anesthesia is an essential component within a multidisciplinary setting to optimize the care for high-risk patients and minimize the risk of intra- and postoperative complications. These data support the need for a multidisciplinary standardized treatment protocol for multi-morbid patients with aortic and mitral stenosis where a trans-vascular approach is not eligible. Nevertheless, a simplified regimen using the PVB has been deemed appropriate in the management of thoracic surgery in several studies $(10,11,22,23)$. PVB is advantageous over thoracic epidural block due to the unilateral nature of the block allowing greater hemodynamic stability, a lack of urinary retention, nausea and vomiting (24). Hence, a multimodal analgesia approach including regional anesthetic techniques for thoracic surgery in the case of transcatheter transapical valve implantation may reduce the likelihood of the development of postoperative respiratory, hemodynamic complications and reduce opioid requirements.

\section{Limitation}

The present study was performed at single tertiary care medical center. However, it represents our preliminary results of fast-track anesthesia on a high-risk group of patients undergoing this specific cardiac surgical procedure. Another limitation is the small patient cohort and the absence of data on a control group treated with general anesthesia including, intubation and muscle relaxation.

\section{Conclusions}

Paravertebral blockade as part of fast-track anesthesia management during a lateral mini thoracotomy for transapical aortic and mitral valve replacement in highrisk patients is a possible approach to avoid endotracheal intubation and the use of muscle relaxant. Fast recovery times with fewer pulmonary complications were observed. These promising results could encourage further consideration of this approach in such cardiac surgery patients.

\section{Acknowledgments}

The authors are sincerely grateful to Andreas Sander (Institute of Quality Controlling, West German Heart and Vascular Centre Essen) for this effort and support in data acquisition to finish this work.

Funding: None.

\section{Footnote}

Reporting Checklist: The authors have completed the STROBE reporting checklist. Available at https://dx.doi. org/10.21037/jtd-21-751

Data Sharing Statement: Available at https://dx.doi. org/10.21037/jtd-21-751

Conflicts of Interest: All authors have completed the ICMJE uniform disclosure form (available at https:// dx.doi.org/10.21037/jtd-21-751). Thorsten Brenner reports receiving honoraria for lectures, presentations, speakers bureaus, manuscript writing or educational events from CSL Behring GmbH, Schöchl medical education GmbH, Biotest AG, Baxter Deutschland GmbH, Boehringer Ingelheim Pharma GmbH, Astellas Pharma GmbH, B. Braun Melsungen AG, MSD Sharp \& Dohme GmbH. As well as participation on a Data Safety Monitoring Board or Advisory Board from Baxter Deutschland $\mathrm{GmbH}$. Besides, research funding from 
Deutsche Forschungsgemeinschaft (DFG), Dietmar Hopp Stiftung, Stiftung Universitätsmedizin Essen. Heidelberger Stiftung Chirurgie, Innovationsfonds des Gemeinsamen Bundesausschusses (G-BA). The other authors have no conflicts of interest to declare.

Ethical Statement: The authors are accountable for all aspects of the work in ensuring that questions related to the accuracy or integrity of any part of the work are appropriately investigated and resolved. The study was conducted in accordance with the Declaration of Helsinki (as revised in 2013). The present study obtained IRB approval (Ref\# 20-9733-BO). All Patients signed and gave informed consent before taking part of this type of anesthesia and agreed to evaluate their data anonymously.

Open Access Statement: This is an Open Access article distributed in accordance with the Creative Commons Attribution-NonCommercial-NoDerivs 4.0 International License (CC BY-NC-ND 4.0), which permits the noncommercial replication and distribution of the article with the strict proviso that no changes or edits are made and the original work is properly cited (including links to both the formal publication through the relevant DOI and the license). See: https://creativecommons.org/licenses/by-nc-nd/4.0/.

\section{References}

1. Iung B, Baron G, Butchart EG, et al. A prospective survey of patients with valvular heart disease in Europe: The Euro Heart Survey on Valvular Heart Disease. Eur Heart J 2003;24:1231-43.

2. Shehada SE, Öztürk Ö, Wottke M, et al. Propensity score analysis of outcomes following minimal access versus conventional aortic valve replacement. Eur J Cardiothorac Surg 2016;49:464-9; discussion 469-70.

3. Shehada SE, Elhmidi Y, Mourad F, et al. Minimal access versus conventional aortic valve replacement: a metaanalysis of propensity-matched studies. Interact Cardiovasc Thorac Surg 2017;25:624-32.

4. Thourani VH, Kodali S, Makkar RR, et al. Transcatheter aortic valve replacement versus surgical valve replacement in intermediate-risk patients: a propensity score analysis. Lancet 2016;387:2218-25.

5. Reardon MJ, Van Mieghem NM, Popma JJ, et al. Surgical or Transcatheter Aortic-Valve Replacement in Intermediate-Risk Patients. N Engl J Med 2017;376:1321-31.
6. Mack MJ, Leon MB, Thourani VH, et al. Transcatheter Aortic-Valve Replacement with a Balloon-Expandable Valve in Low-Risk Patients. N Engl J Med 2019;380:1695-705.

7. Popma JJ, Deeb GM, Yakubov SJ, et al. Transcatheter Aortic-Valve Replacement with a Self-Expanding Valve in Low-Risk Patients. N Engl J Med 2019;380:1706-15.

8. Beckmann A, Meyer R, Lewandowski J, et al. German Heart Surgery Report 2018: The Annual Updated Registry of the German Society for Thoracic and Cardiovascular Surgery. Thorac Cardiovasc Surg 2019;67:331-44.

9. Simonato $M$, Whisenant $B$, Ribeiro HB, et al. Transcatheter Mitral Valve Replacement After Surgical Repair or Replacement: Comprehensive Midterm Evaluation of Valve-in-Valve and Valve-in-Ring Implantation From the VIVID Registry. Circulation 2021:143:104-16.

10. Davies RG, Myles PS, Graham JM. A comparison of the analgesic efficacy and side-effects of paravertebral vs epidural blockade for thoracotomy--a systematic review and meta-analysis of randomized trials. Br J Anaesth 2006;96:418-26.

11. Baidya DK, Khanna P, Maitra S. Analgesic efficacy and safety of thoracic paravertebral and epidural analgesia for thoracic surgery: a systematic review and meta-analysis. Interact Cardiovasc Thorac Surg 2014;18:626-35.

12. Huskisson EC. Measurement of pain. Lancet 1974;2:1127-31.

13. Scott J, Huskisson EC. Graphic representation of pain. Pain 1976;2:175-84.

14. Okitsu K, Iritakenishi T, Iwasaki M, et al. Paravertebral block decreases opioid administration without causing hypotension during transapical transcatheter aortic valve implantation. Heart Vessels 2016;31:1484-90.

15. Long DR, Friedrich S, Eikermann M. High intraoperative opioid dose increases readmission risk in patients undergoing ambulatory surgery. $\mathrm{Br} \mathrm{J}$ Anaesth 2018;121:1179-80.

16. Long DR, Lihn AL, Friedrich S, et al. Association between intraoperative opioid administration and 30day readmission: a pre-specified analysis of registry data from a healthcare network in New England. Br J Anaesth 2018;120:1090-102.

17. McLean DJ, Diaz-Gil D, Farhan HN, et al. Dosedependent Association between Intermediate-acting Neuromuscular-blocking Agents and Postoperative Respiratory Complications. Anesthesiology 2015;122:1201-13. 
18. Kirmeier E, Eriksson LI, Lewald H, et al. Post-anaesthesia pulmonary complications after use of muscle relaxants (POPULAR): a multicentre, prospective observational study. Lancet Respir Med 2019;7:129-40.

19. Grabitz SD, Rajaratnam N, Chhagani K, et al. The Effects of Postoperative Residual Neuromuscular Blockade on Hospital Costs and Intensive Care Unit Admission: A Population-Based Cohort Study. Anesth Analg 2019;128:1129-36.

20. Covello RD, Landoni G, Zangrillo A. Anesthetic management of transcatheter aortic valve implantation. Curr Opin Anaesthesiol 2011;24:417-25.

21. Cobey FC, Ferreira RG, Naseem TM, et al. Anesthetic and perioperative considerations for transapical transcatheter aortic valve replacement. J Cardiothorac

Cite this article as: Haddad A, Szalai C, van Brakel L, Elhmidi Y, Arends S, Rabis M, Pop A, Ruhparwar A, Brenner T, Shehada SE. Fast-track anesthesia in lateral mini-thoracotomy for transapical transcatheter valve implantation. J Thorac Dis 2021;13(8):4853-4863. doi: 10.21037/jtd-21-751
Vasc Anesth 2014;28:1075-87.

22. Joshi GP, Bonnet F, Shah R, et al. A systematic review of randomized trials evaluating regional techniques for postthoracotomy analgesia. Anesth Analg 2008;107:1026-40.

23. Dhole S, Mehta Y, Saxena H, et al. Comparison of continuous thoracic epidural and paravertebral blocks for postoperative analgesia after minimally invasive direct coronary artery bypass surgery. J Cardiothorac Vasc Anesth 2001;15:288-92.

24. Heinke TL, Cagle BL, Guldan GJ 3rd, et al. Continuous Paravertebral Blockade for Post-Thoracotomy Pain Following Transapical Transcatheter Aortic Valve Replacement: A Retrospective Analysis. J Cardiothorac Vasc Anesth 2017;31:e63-5. 